\section{(6) OPEN ACCESS}

\title{
The association between hospitalisation for childhood head injury and academic performance: evidence from a population e-cohort study
}

\author{
Belinda J Gabbe, ${ }^{1,2}$ Caroline Brooks, ${ }^{1}$ Joanne C Demmler, ${ }^{1}$ Steven Macey, ${ }^{1}$ \\ Melanie A Hyatt, ${ }^{1}$ Ronan A Lyons ${ }^{1,2,3}$
}

${ }^{1}$ College of Medicine, Swansea University, Swansea, UK ${ }^{2}$ Department of Epidemiology and Preventive Medicine, Monash University, Melbourne, Victoria, Australia

Public Health Wales NHS Trust, Cardiff, UK

\section{Correspondence to} Professor Belinda Gabbe, Department of Epidemiology and Preventive Medicine, Monash University, The Alfred Centre, Commercial Rd, Melbourne, VIC 3004 Australia;

belinda.gabbe@monash.edu

Received 23 September 2013 Revised 24 November 2013 Accepted 6 December 2013 Published Online First 13 January 2014

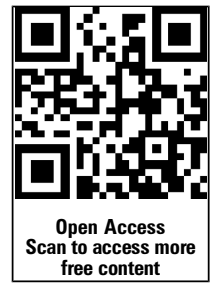

\section{ABSTRACT}

Background Childhood head injury has the potential for lifelong disability and burden. This study aimed to establish the association between admission to hospital for childhood head injury and early academic performance.

Methods The Wales Electronic Cohort for Children (WECC) study is comprised of record-linked routinely collected data, on all children born or residing in Wales. Anonymous linking fields are used to link child and maternal health, environment and education records. Data from WECC were extracted for children born between September 1998 and August 2001. A Generalised Estimating Equation model, adjusted for clustering based on the maternal identifier as well as other key confounders, was used to establish the association between childhood head injury and performance on the Key Stage 1 (KS1) National Curriculum assessment administered to children aged 5-7 years. Head injury was defined as an emergency admission for $>24 \mathrm{~h}$ for concussion, skull fracture or intracranial injury prior to KS1 assessment.

Results Of the 101892 eligible children, KS1 results were available for 90661 (89\%), and 290 had sustained a head injury. Children who sustained an intracranial injury demonstrated significantly lower adjusted odds of achieving a satisfactory KS1 result than children who had not been admitted to hospital for head injury (adjusted OR 0.46, 95\% Cl 0.30 to 0.72 ). Conclusions The findings of this population e-cohort study quantify the impact of head injury on academic performance, highlighting the need for enhanced head injury prevention strategies. The results have implications for the care and rehabilitation of children admitted to hospital with head injury.

\section{INTRODUCTION}

Head injury is a leading cause of death and disability worldwide, ${ }^{1}$ with an overall incidence of 200 hospitalisations per 100000 population at risk per year. ${ }^{2}$ The age distribution of head injury is generally tri-modal, with peaks in early childhood, late adolescence and the elderly. ${ }^{2}$ Childhood head injury represents a particular public health problem due to the potential for lifelong disability and burden. $^{3-5}$

Numerous studies have reported cognitive, emotional, functional and behavioural outcome deficits following head injury sustained in childhood. ${ }^{36-15}$ A critical outcome following paediatric head injury is the capacity to attain adequate educational performance. $^{4}$ 16-19 Limitations in academic performance can have profound short-term and long-term individual and societal costs. ${ }^{16}$

Previous studies have reported negative impacts of childhood head injury on school and academic performance directly, or factors which may contribute to reduced academic performance, ${ }^{3} \quad 4 \quad 6-8 \quad 10-12 \quad 18-20$ while other authors have suggested an injury effect rather than a specific head injury effect when they controlled for preinjury factors. ${ }^{21}$ Most studies, to date, have been limited to small sample sizes, and reported issues with selection bias, loss to follow-up, differing follow-up times and variable inclusion criteria. $^{3}{ }^{4} \quad 6-8 \quad 10 \quad 11 \quad$ 18-20 None have addressed the research question using a population-based approach. Therefore, this study aimed to establish the relationship between head injury resulting in hospitalisation sustained in the early years of life, and early academic performance, using a population-based data linkage approach.

\section{METHODS}

\section{Setting}

The Wales Electronic Cohort for Children (WECC) was set up within the Health Information Research Unit at Swansea University, UK using the Secure Anonymised Information Linkage (SAIL) databank. ${ }^{22}$ WECC is a total, population-anonymised e-cohort study of all children $(n=804290)$ living in Wales and born between 1990 and 2008..$^{23-25}$ Eligible WECC participants were identified from the Welsh Demographic Service, National Community and Child Health Database and Office for National Statistics (births and death records). Anonymous linking fields (ALF) were used to link children to their health, maternal health (via maternal ALFs), residential, environmental and education records, where available. ${ }^{22}{ }^{25}$ Every person in Wales is allocated an ALF which is derived from an encrypted National Health Service (NHS) Number used for linkage purposes and is essentially a unique identifier for the linkage system.

Data held in the SAIL system are anonymised and were obtained with the permission of the relevant Caldicott Guardian/Data Protection Officer; therefore, the National Research Ethics Service has stated that no ethical review is required. Approval was granted from the Health Information Research Unit Information Governance Review Panel (IGRP) to use the data to answer the study question.

Individual-level anonymised data on these children were obtained from a further six data sources including: General Practice data, inpatient and outpatient data from the Patient Episode Database for 
Wales (PEDW), data from the Congenital Anomaly Register and Information Services, free school meal entitlement and environmental data from the National Pupil Database and formal educational data from the Pupil Level Annual School Census.

\section{Participants}

Formal educational assessment data from the National Pupil Database and Pupil Level Annual School Census were only available between the years 2003 and 2008 for children of relevant ages (age 5-7 years) for KS1 assessment in WECC. Therefore, the study population for this analysis of the cohort was children who were born within Wales between 1 September 1995 and 31 August 2001 (6 academic school years). ${ }^{25}$ We excluded stillbirths, deaths before the KS1 assessment date, and children with special educational needs school action, and/or statemented status.

\section{Procedures}

The outcome of interest was a satisfactory performance on the KS1 National Curriculum assessment administered to children aged 5-7 years. For the KS1, teachers are required to summarise their judgements on children's attainment in relation to the National Curriculum level descriptions for each eligible child. The KS1 assessment includes a phonics test and assessment task administered informally as part of normal classroom activity so that children may not know that they are being formally assessed. The tests and tasks are standardised for administration by teachers. The results inform teachers' overall assessments in English, mathematics and science. Performance against the KS1 criteria was obtained from the National Pupil Database and Pupil Level Annual School Census datasets. Pupils are classified not by individual scores, but by categories. The two categories are: level achieved or not achieved. The PEDW, which captures data for all inpatient care provided at NHS hospitals in Wales, was used to identify head injury cases in the participating children. A head injury was defined as an emergency admission for $>24 \mathrm{~h}$, with a relevant principal 10th revision of the International Classification of Diseases (ICD-10) diagnosis of concussion (S06.0), skull fracture (S02.0, S02.1, S02.7) or intracranial injury (S06.1 to S06.9). The date of admission was also obtained to enable identification of head injuries prior to KS1 assessment.

Potential confounders of the association between head injury and academic performance were obtained from data held within WECC. Week of birth and gender were obtained from the Welsh Demographic Service. The age at the time of the KS1 assessment was derived from the week of birth and date of completion of the KS1 assessment. The time since injury was derived from the date of hospital admission and the date of KS1 assessment. The Townsend Index of Disadvantage and Deprivation is a census-based index of material deprivation calculated by the combination of four census variables (unemployment as a percentage of those aged 16 years and over who are economically active; non-car ownership, as a percentage of all households; non-home ownership as a percentage of all households; and household overcrowding), and was obtained for Lower Super Output Area in which the child resides (median population 1500), identified from the Welsh Demographic Service. The higher the Townsend Index score, the more deprived and disadvantaged the Lower Super Output Area. For the purposes of this study, quintiles of the overall Townsend Deprivation Index were used to quantify levels of social deprivation in the cohort. Birth weight (in grams), gestational age at birth (in weeks) and the Apgar scores were obtained from
National Community and Child Health Database and Office of National Statistics birth records. Apgar is a quick test performed on a baby at 1 and $5 \mathrm{~min}$ after birth. The Apgar score is comprised of five items (breathing effort, heart rate, muscle tone, reflexes, skin colour), each measured on a scale from 0 to 2 and summed to provide a quick assessment (scored 1-10) of the health of a newborn child.

\section{Data analysis}

Summary statistics were used to describe the profile of head injured and children without head injury in the cohort. Frequencies and percentages were used for categorical variables. For continuous variables, the mean and SD, or the median and IQR, was used depending on the distribution of the data. Comparison of baseline characteristics by head injury status was performed using $\chi^{2}$ statistics for categorical variables, independent $t$ tests for normally distributed variables, and Mann-Whitney $\mathrm{U}$ tests for skewed variables. A Bonferroni procedure was used to adjust the significance levels for multiple comparisons, with a $\mathrm{p}$ value $<0.008$ considered significant.

Because of the potential for correlation between children of the same family or household, a Generalised Estimating Equation (GEE) approach, adjusted for clustering based on the maternal ALF, was used to assess the association between head injury and performance on the KS1 assessment. The model was also adjusted for potential confounders identified a priori. These included the Townsend Index, age at the time of testing, gender, Apgar test at birth, gestational age and birth weight. A GEE approach allows for more robust SEs of the adjusted OR (AOR), minimising an overestimation or underestimation of the effect between head injury and academic outcome that could be partially explained by correlation between children from the same families. ${ }^{26}$ The unadjusted $\mathrm{OR}$ and the AOR, and $95 \%$ CIs of these estimates, were calculated for the GEE models. All analyses were performed using Stata V.11.2 (StatCorp, College Station, Texas, USA).

\section{RESULTS}

There were 101892 eligible children in the study timeframe, and KS1 results were available for 90661 (89\%) (figure 1). Key Stage 1 results were missing for $30(9.4 \%)$ head injured children, and 11201 (11.0\%) children without head injury. There was no association between head injury status and loss to follow-up (ie, absence of KS1 results) $\left(\mathrm{X}_{1}^{2}=0.89, \mathrm{p}=0.35\right)$.

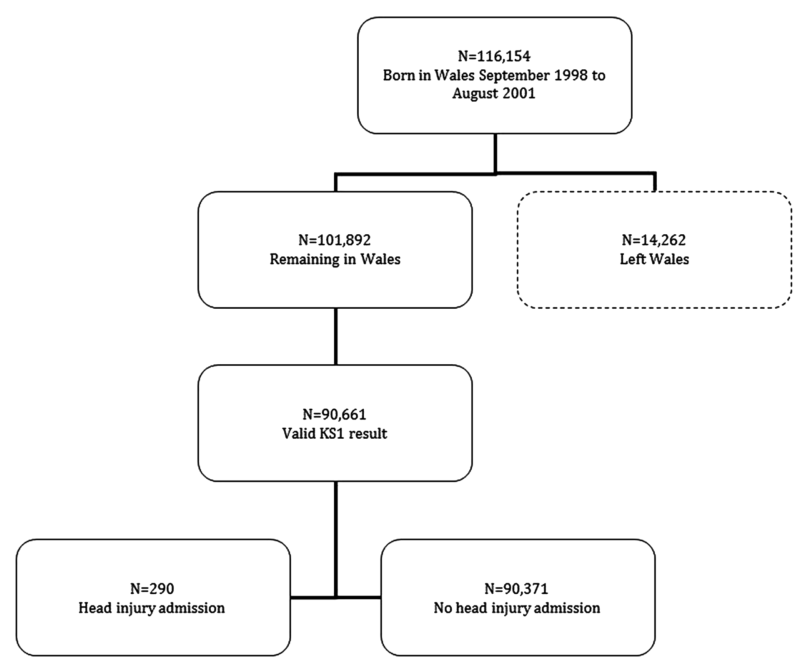

Figure 1 Flow of participants through the study. 
Table 1 displays the characteristics of the population with complete KS1 results by head injury status. Of the 90661 children, $290(0.3 \%)$ had sustained a head injury. The most common principal diagnosis was skull fracture $(n=153)$, followed by intracranial injury $(n=107)$ and concussion $(n=30)$. The median (IQR) age at the time of head injury was $1.3(0.7-3.1)$ years with a range of 0.01 to 7.2 years. The median (IQR) time from injury to KS1 assessment was $6.1(4.2-6.7)$ years with a range of 0.2 to 7.5 years. There was no difference between the group with head injury, and those not sustaining a head injury, with respect to age at the time of KS1 assessment $(t=-1.09, p=0.28)$, birth weight $(t=1.13, p=0.26)$, and gestational age $(t=1.05, p=0.30)$. Apgar score was associated with head injury status $(\mathrm{z}=-2.46, \mathrm{p}=0.01)$.

Of the 90371 children without head injury, 73057 (81\%) had achieved a satisfactory KS1 assessment result. For the head injury groups, $77 \%$ of concussion, $74 \%$ of skull fracture and $66 \%$ of intracranial injury cases had achieved a satisfactory KS1 result. Table 2 shows the results of the GEE modelling of the association between head injury and KS1 achievement. The Apgar score was missing for almost half the cases and was excluded from the multivariable model. Children who sustained an intracranial injury demonstrated significantly lower odds of achieving a satisfactory KS1 result than children who had not been admitted to hospital for head injury, after adjusting for gender, levels of deprivation, age at the time of testing, birth weight and gestational age (table 2). There was no evidence of a difference in the adjusted odds of achieving a satisfactory KS1 result when comparing children admitted to hospital for skull fracture or concussion, with children who had not been admitted to hospital for head injury (table 2). Higher levels of deprivation reduced the adjusted odds of a satisfactory KS1 result, while females and higher birthweight children, demonstrated significantly higher adjusted odds of a satisfactory KS1 assessment (table 2).

Table 1 Characteristics of participants

\begin{tabular}{|c|c|c|}
\hline Population descriptor & $\begin{array}{l}\text { No head injury } \\
(\mathrm{n}=90371)\end{array}$ & $\begin{array}{l}\text { Head injury } \\
(n=290)\end{array}$ \\
\hline \multicolumn{3}{|l|}{ Gender* } \\
\hline \multicolumn{3}{|l|}{$\mathrm{n}(\%)$} \\
\hline Male & $46348(51.3)$ & $162(55.9)$ \\
\hline Female & 44019 (48.7) & $128(44.1)$ \\
\hline \multicolumn{3}{|c|}{ Townsend deprivation index quintilet } \\
\hline \multicolumn{3}{|l|}{$\mathrm{n}(\%)$} \\
\hline $\begin{array}{l}1 \text { (least deprived) } \\
\text { (reference) }\end{array}$ & 17395 (19.4) & $47(16.4)$ \\
\hline 2 & 16863 (18.8) & $43(15.0)$ \\
\hline 3 & $17301(19.3)$ & $56(19.5)$ \\
\hline 4 & 17909 (19.9) & $65(22.6)$ \\
\hline 5 (most deprived) & $20339(22.6)$ & $76(26.5)$ \\
\hline \multicolumn{3}{|l|}{ Apgar score } \\
\hline Median (IQR) & $9(5-9)$ & $9(7-9)$ \\
\hline \multicolumn{3}{|l|}{ Gestational age§ } \\
\hline Mean (SD) weeks & $39.3(2.1)$ & $39.2(2.1)$ \\
\hline \multicolumn{3}{|l|}{ Birth weightๆ } \\
\hline Mean (SD) kg & $3.4(0.6)$ & $3.3(0.6)$ \\
\hline \multicolumn{3}{|l|}{ Age at KS1 assessment } \\
\hline Mean (SD) years & $7.3(0.3)$ & $7.3(0.3)$ \\
\hline
\end{tabular}

Table 2 Association between head injury and satisfactory performance on KS1 assessment (adjusted ORs from model including all table variables)

\begin{tabular}{lll}
\hline Predictor & OR $(95 \% \mathrm{Cl})$ & AOR $(95 \% \mathrm{Cl})$ \\
\hline $\begin{array}{l}\text { Head injury } \\
\quad \text { None (reference) }\end{array}$ & 1 & 1 \\
$\quad$ Skull fracture & $0.73(0.50$ to 1.09$)$ & $0.79(0.52$ to 1.18$)$ \\
$\quad$ Concussion & $0.85(0.33$ to 2.16$)$ & $0.87(0.31$ to 2.49$)$ \\
$\quad$ Intracranial injury & $0.50(0.33$ to 0.75$)$ & $0.46(0.30$ to 0.72$)$ \\
Gender & - & 1 \\
$\quad$ Male (reference) & & $1.95(1.87$ to 2.03$)$ \\
$\quad$ Female & - & 1 \\
Townsend deprivation index quintile & & $0.64(0.59$ to 0.69$)$ \\
1 (Least deprived) (reference) & - & $0.49(0.45$ to 0.52$)$ \\
2 & & $0.38(0.35$ to 0.41$)$ \\
3 & & $0.26(0.24$ to 0.28$)$ \\
4 & - & $2.77(2.60$ to 2.97$)$ \\
5 (Most deprived) & - & $1.41(1.35$ to 1.47$)$ \\
Age at KS1 assessment (years) & - & $1.01(1.00$ to 1.03$)$ \\
Birth weight (kg) & & \\
Gestational age (weeks) &
\end{tabular}

\section{DISCUSSION}

Educational achievement is strongly related to life chances. Poor levels of achievement contribute to the development and persistence of inequalities in health. Therefore, school reintegration and the capacity to thrive academically after head injury are critical for reducing the impacts of head injury and the potential for lifelong burden. This study used an electronic population cohort design, based on anonymised linkage of routine health and social datasets, to explore the relationship between head injury in early childhood and educational attainment. There was a significant association between nature of head injury and likelihood of achieving a suboptimal educational attainment result in the KS1 assessments. Children who were admitted to hospital for intracranial injuries demonstrated twice the odds of suboptimal KS1 levels as those not admitted to hospital for head injury. Children admitted for skull fracture or concussion demonstrated comparable odds of achieving expected levels of performance in the KS1 assessments when compared with children without head injury. Deprivation levels were also strongly related to educational achievement.

Our study used an electronic cohort approach across an entire population, representing the only population-based study to investigate the association between childhood head injury and early academic performance. This approach used data from linked health and education datasets, enabling a much higher number of participants, greater statistical power to explore the relationship between exposure and outcome, and reduction of the potential for selection bias highlighted as an issue for numerous previous studies where parents or children are invited to participate in the study. The WECC study allowed all children without head injury to act as the comparator group, with adjustment for key covariates known to be important to the outcome and captured through routine data collection. Therefore, the potential for proxy reporting or recall bias of covariates was likely to be lower in this study. Loss to follow-up was also minimised through the use of data linkage, given the reporting requirements of schools to databases, and the capacity to identify movement of children out of Wales. Using the 
e-cohort approach of WECC will also provide a relatively low-cost platform for additional follow-up of WECC children who have not yet reached the KS1 assessment, and will also allow exploration of the relationship with later educational milestones, essentially providing a longitudinal study with multiple time points for follow-up.

Despite the significant strengths of this study, there were limitations. Previous studies have used a number of standardised tests or measures to assess school performance (eg, school domain of health-related quality-of-life measures, teacher reports) and the skills needed for academic performance (eg, intelligence, attention, processing, behaviour, etc). In our study, the measure of academic performance used was a global measure of achievement which has been criticised as an insensitive measure for paediatric head injury. ${ }^{17}$ Efforts are made to standardise the tests and tasks, and to monitor the conduct of administration. However, the need for the test to be administered by different teachers and schools may result in variability in assessments. Nevertheless, the findings of this large cohort study were clear, and the KS1 is an important educational attainment milestone in the UK school system. Head injury was identified using ICD-10 diagnosis codes from PEDW, which limited the capacity to adjust for head injury severity, as there is no inbuilt severity scale within the ICD-10 system. For example, there is a single code for a traumatic subdural haemorrhage, despite wide potential variation in the size and location of the haemorrhage. The number of admissions for concussion was low, most likely as this type of injury is not usually admitted, and studies have shown lower sensitivity for identifying concussion using ICD codes. ${ }^{27} 28$ The findings will not reflect all concussion injury, and the statistical power to provide a precise estimate of this relationship was limited. Nevertheless, our findings were, overall, consistent with the literature suggesting that the impact on academic performance of intracranial injury differs from skull fracture and concussion. Additionally, as with all observational studies, causation cannot be assured. While attempts were made to adjust for key potential confounders identified in the literature, missing data precluded the investigation of some potential confounders (eg, Apgar scores), and it is possible that other environmental and individual factors not accounted for in the study could partially explain the findings.

Twenty-nine per cent of children admitted to hospital for $>24 \mathrm{~h}$ recorded unsatisfactory academic performance in the UK's Key Stage 1 assessments performed in children 5-7 years of age, although this varied by nature of injury, and was as high as $34 \%$ for intracranial injury cases. These findings are consistent with the published literature focused on hospitalised head injury in childhood. Studies by Kinsella et al ${ }^{18}{ }^{19}$ of children admitted to hospital with traumatic brain injury (TBI) in Australia reported the prevalence of special education needs ranging from $17 \%$ to $31 \%, 1$ to 2 years postinjury. Hawley studied 67 children with TBI and compared their outcomes with 14 matched, uninjured controls, and found that $24 \%$ of TBI patients had special education needs at 2-3 years postinjury. ${ }^{4}$ In a similar study, involving 97 children admitted to hospital for $>24 \mathrm{~h}$ with TBI, the proportion with school problems at follow-up was higher than noted for the 31 control children (27\% vs $4 \%)^{3}$ Ewing-Cobbs et al found that $48 \%$ of 23 children with TBI achieved 'unfavourable' academic performance more than 3 years postinjury, compared to $5 \%$ of the 21 children in the community comparison group. ${ }^{16}$ Many studies reported a dose-response relationship between head injury severity and poorer academic performance. ${ }^{3} 7$ 18-20

Poorer academic achievement following childhood head injury has been attributed to both environmental and individual factors. Behavioural problems, ${ }^{3-5} 20$ deficits in memory, 3515192029 attention, ${ }^{5} 830$ executive function, ${ }^{15} 20$ information processing speeds, ${ }_{19}^{19}$ motor skills, ${ }^{5}$ and other neurocognitive sequelae ${ }^{3} 5^{15} 19$ have all been identified in children following head injury. These factors can impact on school readiness and learning capacity, and socialisation necessary for successful school performance. In addition, factors related to the school's capacity to integrate a child following head injury and the capacity to understand and adapt to child needs have been highlighted by authors as issues with academic performance following childhood head injury. ${ }^{12}{ }^{31}$ In recognition of the role the school plays in reintegration of children into the academic environment after head injury, school re-entry criteria have been added to recently developed quality of care indicators for the rehabilitation of children with TBI. ${ }^{32}$

Our findings of a negative impact on academic performance of male gender, ${ }^{33}{ }^{34}$ higher levels of deprivation and lower birth weight, ${ }^{35}{ }^{36}$ are consistent with the wider academic performance literature. The importance of socioeconomic status and deprivation scores in childhood head injury has been highlighted by several authors. ${ }^{3} 4715$ In our study, the proportion of head injured children classified by postcode to the highest deprivation quintile was $27 \%$, while Hawley (2003) reported that $17 \%$ of head injured children were in the very deprived category and two-thirds were deprived. ${ }^{3}$ Low socioeconomic status was an important predictor of poorer outcome in a number of childhood head injury studies. ${ }^{3} 715$

\section{CONCLUSIONS}

The findings of this population e-cohort study quantify the impact of head injury on one measure of academic performance,

\section{What is already known on this subject}

- Head injury is a leading cause of death and disability worldwide, with childhood head injury representing a particular public health problem due to the potential for lifelong disability and burden.

- A critical outcome following paediatric head injury is the capacity to attain adequate educational performance, as limitations in academic performance can have profound short and long-term individual and societal costs.

- Although previous studies have reported negative impacts of childhood head injury on school and academic performance directly, most have been limited to small sample sizes, and reported methodological limitations.

What this study adds

- The key finding of this population e-cohort study was that children who were admitted to hospital for intracranial injuries were less than half as likely to achieve expected school performance levels as those not admitted to hospital for head injury.

- The results highlight the need for effective strategies to prevent childhood head injury.

- Recently developed clinical care indicators, which include school re-entry criteria, could assist in the rehabilitation after childhood head injury. 
highlighting the need for enhanced head injury prevention strategies. The results also have implications for the care and rehabilitation of children admitted to hospital with head injury, including school reintegration, and could be guided by newly developed clinical care indicators for childhood TBI. ${ }^{32}$

Contributors BJG and RAL conceived the project. All authors contributed to the study design. BJG undertook the analysis and BJG, MAH and RAL drafted the manuscript. All authors reviewed the manuscript and approved the final version for submission.

Funding The development of WECC was supported by a Translational Health Research Platform Award from the National Institute for Social Care and Health Research (grant reference: TPR08-006). The work was undertaken with the support of The Centre for the Development and Evaluation of Complex Interventions for Public Health Improvement (DECIPHer), a UKCRC Public Health Research: Centre of Excellence. Funding from the British Heart Foundation, Cancer Research UK, Economic and Social Research Council (RES-590-28-0005), Medical Research Council, the Welsh Government and the Wellcome Trust (WT087640MA), under the auspices of the UK Clinical Research Collaboration, is gratefully acknowledged. This study was also supported by the Centre for the Improvement of Population Health through E-records Research (CIPHER), one of four UK e-health Informatics Research Centres funded by a joint investment from: Arthritis Research UK, the British Heart Foundation, Cancer Research UK, the Chief Scientist Office (Scottish Government Health Directorates), the Economic and Social Research Council, the Engineering and Physical Sciences Research Council, the Medical Research Council, the National Institute for Health Research, the National Institute for Social Care and Health Research (Welsh Government) and the Wellcome Trust (Grant reference: MR/ K006525/1). Belinda Gabbe was supported by a National Health and Medical Research Council of Australia Career Development Fellowship (APP1048731) during the preparation of this manuscript.

\section{Competing interests None.}

Ethics approval Data held in the SAIL system are anonymised and were obtained with the permission of the relevant Caldicott Guardian/Data Protection Officer; therefore, the National Research Ethics Service has stated that no ethical review is required. Approval was granted from the Health Information Research Unit Information Governance Review Panel to use the data to answer the study question.

Provenance and peer review Not commissioned; externally peer reviewed.

Data sharing statement The data included in this project are not freely available. Requests for access to data from the participating datasets would need to be through the data custodians.

Open Access This is an Open Access article distributed in accordance with the terms of the Creative Commons Attribution (CC BY 3.0) license, which permits others to distribute, remix, adapt and build upon this work, for commercial use, provided the original work is properly cited. See: http://creativecommons.org/ licenses/by/3.0/

\section{REFERENCES}

1 Jennett B. Epidemiology of head injury. J Neurol Neurosurg Psychiatry 1996;60:362-9.

2 Bruns Jnr J, Hauser W. The epidemiology of traumatic brain injury: a review. Epilepsia 2003;44:2-10

3 Hawley C. Reported problems and their resolution following mild, moderate and severe traumatic brain injury amongst children and adolescents in the UK. Brain Inj 2003; 17:105-29.

4 Hawley C. Behaviour and school performance after head injury. Brain Inj 2004;18:645-59.

5 Scott-Jupp R, Marlow N, Seddon N, et al. Rehabilitation and outcome after severe head injury. Arch Dis Child 1992;67:222-6.

6 Anderson V, Brown S, Newitt H, et al. Eduational, vocational, psychosocial and quality-of-life outcomes for adult survivors of childhood traumatic brain injury. J Head Trauma Rehabil 2009;24:303-12.

7 Anderson V, Catroppa C, Dudgeon P, et al. Understanding predictors of functional recovery and outcome 30 months following early childhood injury. Neuropsychology 2006;20:42-57.

8 Anderson V, Eren $\mathrm{S}$, Dob $\mathrm{R}$, et al. Early attention impairment and recovery profiles after childhood traumatic brain injury. J Head Trauma Rehabil 2012;27:199-209.

9 Di Battista A, Soo C, Catroppa C, et al. Quality of life in children and adolescents post-TBI: A systematic review and meta-analysis. J Neurotrauma 2012;29:1717-27.
10 Donders J, Warschausky S. Neurobehavioral outcomes after early versus late childhood traumatic brain injury. J Head Trauma Rehabil 2007;22:296-302.

11 Erickson S, Montague E, Gerstle M. Health-related quality of life in children with moderate-to-severe traumatic brain injury. Dev Neurorehabil 2010;10: 175-81.

12 Renstrom B, Soderman K, Domello E, et al. Self-reported health and influence on life situation $5-8$ years after paediatric traumatic brain injury. Brain Inj 2012:26:1405-14.

13 Stancin T, Drotar D, Taylor G, et al. Health-related quality of life of children and adolescents after traumatic brain injury. Pediatrics 2002;109:e34.

14 Stancin T, Kaugars A, Thompson G, et al. Child and family functioning 6 and 12 months after a serious pediatric fracture. J Trauma 2001:51:69-76.

15 Taylor H, Swartwout M, Yeates K, et al. Traumatic brain injury in young children: Postacute effects on cognitive and school readiness skills. J Int Neuropsychol Soc 2008;14:734-45.

16 Ewing-Cobbs L, Prasad M, Kramer L, et al. Late intellectual and academic outcomes following traumatic brain injury sustained during early childhood. J Neurosurg 2006;105:287-96.

17 Johnson D. Head injured children and education: A need for greater delineation and understanding. Br J Educ Psychol 1992;62:404-9.

18 Kinsella G, Prior M, Sawyer M, et al. Neuropsychological deficit and academic performance in children and adolescents following traumatic brain injury. J Pediatr Psychol 1995:20:753-67.

19 Kinsella G, Prior M, Swayer M, et al. Predictors and indicators of academic outcome in children 2 years following traumatic brain injury. J Int Neuropsychol Soc 1997:3:608-16

20 Fulton J, Yeates $\mathrm{K}$, Taylor $\mathrm{H}$, et al. Cognitive predictors of academic achievement in young children 1 year after traumatic brain injury. Neuropsychology 2012;26: 314-22.

21 Babikian T, Satz P, Light R, et al. The UCLA longitudinal study of neurocognitive outcomes following mild pediatric traumatic brain injury. J Int Neuropsychol Soc 2011:17:886-95.

22 Lyons $\mathrm{R}$, Jones $\mathrm{K}$, John $\mathrm{G}$, et al. The SAIL databank: linking multiple health and social care datasets. BMC Med Inform Decis Mak 2009;9:3.

23 Lyons $\mathrm{R}$, Hutchings $\mathrm{H}$, Rodgers $\mathrm{S}$, et al. Development and use of a privacy-protecting total population record linkage system to support observational, interventional, and policy relevant research. Lancet 2012;380:S6. doi:10.1016/ S0140-6736(13)60362-1

24 Hyatt M, Rodgers S, Paranjothy S, et al. The Wales Electronic Cohort for Children (WECC) study. Arch Dis Child Fetal Neonatal Ed 2011;96:Fa18.

25 Hutchings $H$, Evans $A$, Barnes $P$, et al. Do children who move home and schoo frequently have poorer educational outcomes in their early years at school? an anonymised cohort study. PLOS ONE 2013;8:e70601.

26 Hanley J, Negassa A, Edwardes M, et al. Statistical analysis of correlated data using generalized estimating equations: an orientation. Am J Epidemiol 2003;157: 364-75.

27 Carroll C, Cochran J, Guse C, et al. Are we underestimating the burden of traumatic brain injury? surveillance of severe traumatic brain injury using centers for diseas control international classification of disease, ninth revision, clinical modification, traumatic brain injury codes. Neurosurgery 2012;71:1064-70.

28 Shore A, McCarthy M, Serpi T, et al. Validity of administrative data for characterizing traumatic brain injury-related hospitalizations. Brain Inj 2005;19:613-21.

29 Allen D, Hicks G, Bota G. Outcomes after severe trauma at a Northern Canadian regional trauma centre. Can J Surg 1998:41:53-8.

30 Catroppa C, Anderson V, Godfrey C, et al. Attentional skills 10 years post-paediatric traumatic brain injury (TBI). Brain Inj 2011;25:858-69.

31 Mealings M, Douglas J, Olver J. Considering the student perspective in returning to school after TBI: A litereature review. Brain Inj 2012;26:1165-76.

32 Rivara F, Ennis S, Mangione-Smith R, et al. Quality of care indicators for the rehabilitation of children with traumatic brain injury. Arch Phys Med Rehabil 2012:93:381-5

33 Anderson M. Multiple inference and gender differences in the effects of early intervention: a reevaluation of the Abecedarian, Perry Preschool, and early training projects. J Am Stat Assoc 2008;103:1481-95.

34 Cornwell C, Mustard D, Van Parys J. Noncognitive skills and the gender disparities in test scores and teacher assessments: evidence from primary school. J Hum Resources 2013;48:236-64.

35 Resnick M, Gueorguieva R, Carter R, et al. The impact of low birth weight, perinatal conditions, and sociodemographic factors on educational outcome in kindergarten. Pediatrics 1999;104:e74.

36 Hack M, Flannery $D$, Schluchter $M$, et al. Outcomes in young adulthood for very-low-birth-weight infants. N Engl J Med 2002;346:149-57. 